\title{
A comparative study of the prevalence of zinc deficiency among children with acute diarrhoea in SouthWestern Nigeria
}

\author{
Olufunmilola O Abolurin ${ }^{1}$, Oyeku A Oyelami², Saheed B Oseni²
}

1. Department of Paediatrics, Obafemi Awolowo University Teaching Hospitals complex, Ile-Ife, Nigeria. 2. Department of Paediatrics, Obafemi Awolowo University, Ile-Ife, Nigeria.

\section{Emails:}

funlyt@yahoo.com, oyekuoyelami@gmail.com,sbaoseni@gmail.com

\begin{abstract}
Background: Zinc deficiency has been associated with increased incidence, severity and duration of childhood diarrhoea. Objective: The objective of the study was to determine the prevalence of zinc deficiency among under-five children with acute diarrhoea.

Methods: The study was a comparative cross-sectional study in which serum zinc levels were determined using atomic absorption spectrometry in under-five children with acute diarrhoea and in apparently healthy contols. Two hundred and fifty children with acute diarrhoea and 250 controls were studied at the Wesley Guild Hospital, Ilesa, Nigeria.

Results: The diarrhoea patients had a mean \pm SD serum zinc level of $78.8 \pm 35.6 \mu \mathrm{g} / \mathrm{dl}$, while the controls had a mean of $107.3 \pm 46.8 \mu \mathrm{g} / \mathrm{dl}$. The mean serum zinc level was significantly lower in the patients than the controls $(\mathrm{t}=-7.66 ; \mathrm{p}<0.001)$. Furthermore, the prevalence of zinc deficiency was significantly higher among the patients $(30.4 \%$ versus $12.4 \%$ in the controls; $\left.\mathrm{OR}=3.09 ; 95 \% \mathrm{CI}=1.94-4.90 ; \chi^{2}=24.08 ; \mathrm{p}<0.001\right)$. Low social class was associated with a significantly higher prevalence of zinc deficiency among the patients $(\mathrm{p}=0.013)$.

Conclusion: Zinc deficiency is significantly associated with diarrhoea among under-five children in the study community. Hence, routine zinc supplementation should be encouraged for the treatment of diarrhoea, and availability should be ensured.
\end{abstract}

Keywords: Zinc deficiency, diarrhoea, children, Nigeria.

DOI: https://dx.doi.org/10.4314/ahs.v20i1.47

Cite as: Abolurin OO, Oyelami OA, Oseni SB. A comparative study of the prevalence of zinc deficiency among children with acute diarrhoea in SouthWestern Nigeria. Afri Health Sci. 2020;20(1):406-12. https:/ / dx.doi.org/10.4314/abs.v20i1.47

\section{Introduction}

Diarrhoeal disease represents a major public health problem, accounting for almost 10 percent of under-five deaths, with an estimated 0.6 million deaths per year globally. ${ }^{1}$ In Nigeria, diarrhoea accounts for about 16 percent of under-five mortality, with an estimated 150,000 deaths annually. ${ }^{2}$ Zinc is an essential micronutrient that is important for growth and development as well as immune

\section{Corresponding author:}

Olufunmilola O Abolurin,

Department of Paediatrics,

Obafemi Awolowo University

Teaching Hospitals complex, Ile-Ife, Nigeria;

Tel: +2348035176432

Email: funlyt@yahoo.com function. ${ }^{3}$ Zinc deficiency contributes substantially to the morbidity and mortality of young children throughout the world. ${ }^{4}$ It is particularly common in developing countries because the commonly consumed staple foods have low zinc contents and are rich in phytates. Phytates bind zinc and inhibit its absorption, resulting in lower bioavailability of zinc from such food items. ${ }^{4,5}$ A national survey in Nigeria showed that $20 \%$ of under-five children were zinc deficient. ${ }^{6}$

Zinc deficiency is associated with increased occurrence, severity and prolongation of diarrhoeal illnesses in children, resulting in increased morbidity and mortality. ${ }^{7} \mathrm{~A}$ vicious cycle operates between diarrhoea and zinc deficiency such that diarrhoea reduces net absorption of zinc and other nutrients due to rapid intestinal transit and deterioration of the absorptive mucosa. On the other hand, 
zinc deficiency impairs absorption of water and electrolytes as well as clearance of aetiologic pathogens, thus delaying the termination of normally self-limiting diarrhoea episodes. ${ }^{8}$

Zinc supplementation has been recommended for the treatment of diarrhoea by the World Health Organization (WHO) and United Nations Children's Fund (UNICEF) since year 2004, ${ }^{9}$ yet access to this essential treatment remains limited in many countries. ${ }^{10}$ Low rates of prescription of zinc for childhood diarrhoea by healthcare workers have previously been reported in Nigeria. ${ }^{11}$ Hence, children who are zinc-deficient may sometimes be deprived of this vital treatment, despite visiting health care facilities for the treatment of diarrhoea.

There have been very few studies geared towards investigating the relationship between zinc deficiency and diarrhoea among Nigerian children, and such studies are not generalizable to other parts of the country because staple foods and their zinc contents vary among different communities. ${ }^{5}$ Children suffering from diarrhoeal diseases are frequently from low socioeconomic class, ${ }^{12}$ and may therefore be at a disadvantage for consuming zinc-rich food items, which are usually expensive. ${ }^{5}$ Furthermore, zinc supplements were not readily available in most of the pharmacy shops in the study community prior to commencement of the present study. The study was therefore carried out to assess the burden of zinc deficiency in our community, especially in relation to diarrhoeal diseases, with the ultimate aim of reducing the morbidity and mortality associated with diarrhoea.

\section{Methods}

The study was a comparative cross-sectional study involving under-five children with acute diarrhoea. Acute diarrhoea was defined as the passage of unusually loose or watery stools, at least three times in a 24 hour period, with duration less than 14 days. The subjects were children between the ages of six to 59 months who had presented with acute diarrhoea. They were recruited consecutively at the under-five welfare clinic and the children's emergency ward of the Wesley Guild Hospital (WGH), Ilesa, Osun State, Nigeria. The WGH is one of the units of the Obafemi Awolowo University Teaching Hospitals' complex (OAUTHC), Ile-Ife, Osun state, Nigeria.

Sample size was estimated using the formula for estimat- ing proportions, ${ }^{13}$ with prevalence of zinc deficiency taken as $20 \%,{ }^{6}$ sampling error as $5 \%$ and confidence interval as $95 \%$. Children with severe undernutrition (z-score below -3 on a WHO growth chart, or presence of oedema), sepsis, sickle cell anaemia and HIV infection were excluded from the study, as these conditions have been associated with zinc deficiency. ${ }^{14-17}$ Retroviral screening was done for all the children, while relevant investigations were done to exclude sepsis or sickle cell anaemia, only in children who had suggestive history or examination findings. Apparently healthy children without diarrhoea were recruited as controls and were matched for age and sex with the subjects. The controls were recruited from the under-five welfare clinic of the WGH. They included children who presented for immunization or routine blood tests such as haemoglobin genotype.

Ethical clearance was obtained for the study from the Ethics and research committee of the Obafemi Awolowo University Teaching Hospitals' complex (OAUTHC). A written informed consent was obtained from the parent (s) or the accompanying guardian of each of the study participants. History about the nature and duration of diarrhoea as well as socio-economic background were obtained and all the patients were examined. The children were classified into those from high and low social class based on the occupation and highest level of education of their parents. ${ }^{18}$ Anthropometric measurements including weight and height/length were obtained for the assessment of nutritional status and the WHO child growth standards in form of $\mathrm{z}$-scores ${ }^{19}$ were used to classify the nutritional status of the children. Children who had z-score $<-2$, but $\geq-3$, were considered to be underweight, stunted or wasted, using the appropriate WHO growth chart. Signs of dehydration were documented when present. The degree of dehydration was subsequently classified as mild, moderate or severe according to 'the guide to clinical assessment of dehydration'. ${ }^{20}$ Blood samples were collected for zinc assay at presentation, and the serum was separated by centrifugation at 3000 revolutions per minute using a clinical macro-centrifuge. Laboratory quality control was ensured by applying standard clotting times before separation of blood in order to prevent haemolysis, and also by adequate centrifugation procedures to ensure removal of all blood cells, as well as proper storage/refrigeration of serum samples before analysis. Serum zinc levels were determined using atomic absorption spectrophotometry (AAS) at the Central Science 
Laboratory of the Obafemi Awolowo University, Ile-Ife, Nigeria. The AAS machine used was AAnalyst 400 model by PerkinElmer. Values of serum zinc less than $65 \mu \mathrm{g} / \mathrm{dl}$ were considered low as recommended by the IZiNCG (International zinc nutrition consultative group), ${ }^{21}$ and such were classified as zinc deficiency.

Data analysis was done using the statistical programme for social sciences (SPSS) version 16.0. Means and standard deviations (SD) were computed for continuous variables while proportions were calculated for discrete variables. Means were compared using the independent samples t-test $(\mathrm{t})$, while proportions were compared using the Pearson's chi-square test $\left(\chi^{2}\right)$. Probability values $(\mathrm{p})$
$<0.05$ were accepted as statistically significant.

\section{Results}

Of the 250 diarrhoea patients, 147 (58.8\%) were males and $103(41.2 \%)$ were females. Their ages ranged from six to 56 months with mean and standard deviation (SD) of $16.6 \pm 9.4$ months. The controls had a mean age \pm SD of $16.6 \pm 9.3$ months. Table I shows a comparison of the socio-economic and nutritional status of the patients and controls. A significantly higher proportion of the patients were from low social class, compared with the controls ( $p$ <0.001). Underweight, stunting and wasting were also more prevalent among the patients $(\mathrm{p}=0.002,0.009$ and 0.006 , respectively).

Table I: Socio-economic and nutritional status of the subjects and controls.

\begin{tabular}{lcccc}
\hline $\begin{array}{l}\text { Socio- } \\
\text { economic/ Nutritional } \\
\text { status }\end{array}$ & $\begin{array}{c}\text { Subjects } \\
\mathbf{n}(\mathbf{\%})\end{array}$ & $\begin{array}{c}\text { Controls } \\
\mathbf{n}(\mathbf{\%})\end{array}$ & $\begin{array}{c}\text { Total } \\
\mathbf{n}(\mathbf{\%})\end{array}$ & Statistical comparison \\
\hline Social class & & & & \\
Low & $204(81.6)$ & $167(66.8)$ & $371(74.2)$ & $\chi^{2}=14.30$, \\
High & $46(18.4)$ & $83(33.2)$ & $129(25.8)$ & $\mathrm{p}<\mathbf{0 . 0 0 1}$ \\
Total & $250(100.0)$ & $250(100.0)$ & $500(100.0)$ & \\
& & & & \\
Underweight & & & & \\
Underweight & $45(18.0)$ & $21(8.4)$ & $66(13.2)$ & $\chi^{2}=10.05$, \\
Normal & $205(82.0)$ & $229(91.6)$ & $434(86.8)$ & $\mathrm{p}=\mathbf{0 . 0 0 2}$ \\
Total & $250(100.0)$ & $250(100.0)$ & $500(100.0)$ & \\
Stunting & & & & \\
Yes & & & & \\
No & $36(14.4)$ & $18(7.2)$ & $54(10.8)$ & $\chi^{2}=6.73$, \\
Total & $214(85.6)$ & $232(92.8)$ & $446(89.2)$ & $\mathrm{p}=\mathbf{0 . 0 0 9}$ \\
Wasting & $250(100.0)$ & $250(100.0)$ & $500(100.0)$ & \\
Yes & & & & \\
No & $44(17.6)$ & $23(9.2)$ & $67(13.4)$ & $\chi^{2}=7.60$, \\
Total & $206(82.4)$ & $227(90.8)$ & $433(86.6)$ & $\mathrm{p}=\mathbf{0 . 0 0 6}$ \\
\hline
\end{tabular}

The mean \pm SD duration of diarrhoea at presentation was $3.4 \pm 2.5$ days with the duration ranging from one to 13 days. The number of episodes of watery stool per day ranged from three to 12 episodes with a mean \pm $\mathrm{SD}$ of $4.9 \pm 2.2$. A history of fever was present in 182 (72.8\%) of the patients, while 151 (60.4\%) had one or more episodes of vomiting. Reduction in urinary output was reported in $17(6.8 \%)$ of them. One hundred and eighty-two $(72.8 \%)$ of them had no evidence of dehydra- tion while $36(14.4 \%)$ had mild dehydration, 20 (8.0\%) moderate dehydration, and 12 (4.8\%) severe dehydration. Table II shows the mean and classification of serum zinc levels in the patients and controls. The mean \pm SD serum zinc level in the diarrhoea patients was significantly lower than that of the controls $(t=-7.66 ; p<0.001)$. Furthermore, the prevalence of zinc deficiency was significantly higher among the patients than the controls $\left(\chi^{2}=24.08\right.$; $\mathrm{p}<0.001 ;$ OR $=3.09 ; 95 \% \mathrm{CI}=1.94-4.90)$. 
Table II: Mean and classification of serum zinc levels in the patients and controls.

\begin{tabular}{lccc}
\hline Serum zinc & $\begin{array}{c}\text { Patients } \\
(\mathbf{n}=\mathbf{2 5 0})\end{array}$ & $\begin{array}{c}\text { Controls } \\
(\mathbf{n}=\mathbf{2 5 0})\end{array}$ & $\begin{array}{c}\text { Statistical } \\
\text { comparison }\end{array}$ \\
\hline Mean $\pm \mathrm{SD}(\mu \mathrm{g} / \mathrm{dl})$ & $78.8 \pm 35.6$ & $107.3 \pm 46.8$ & $\mathrm{t}=-7.66 ; \mathrm{p}<\mathbf{0 . 0 0 1}$ \\
Low & $76(30.4 \%)$ & $31(12.4 \%)$ & \\
Normal & $174(69.6 \%)$ & $219(87.6 \%)$ & $\chi^{2}=24.08 ; \mathrm{p}<\mathbf{0 . 0 0 1}$ \\
\hline
\end{tabular}

There was no significant correlation between serum zinc levels and duration of diarrhoea $(r=-0.01, \mathrm{p}=0.943)$ or stool frequency $(\mathrm{r}=0.01, \mathrm{p}=0.845)$. Table III shows the relationships between zinc deficiency and other variables among the diarrhoea patients. Fever and low social class were associated with a significantly higher prevalence of zinc deficiency among the patients $(p=0.018$ and 0.013 , respectively). There was no significant difference in the prevalence of zinc deficiency between patients that were underweight and those who were not $(p=0.637)$. Similarly, there was no statistically significant difference in the prevalence of zinc deficiency in relation to stunting $(\mathrm{p}=$ $0.983)$, wasting $(p=0.558)$, vomiting $(p=0.097)$ or the presence of dehydration $(\mathrm{p}=0.409)$ among the patients (Table III). Nevertheless, the prevalence of zinc deficiency was significantly higher among the severely dehydrated patients, compared with those who had mild or moderate dehydration $(p=0.044)$. Table III: Relationships between the prevalence
variables among children with diarrhoea.

\begin{tabular}{|c|c|c|c|c|}
\hline \multirow[t]{2}{*}{ Parameter } & \multicolumn{3}{|c|}{ Zinc status } & \multirow[t]{2}{*}{ Statistical comparison } \\
\hline & $\begin{array}{c}\text { Zinc- } \\
\text { deficient } \\
\text { n }(\%)\end{array}$ & $\begin{array}{c}\text { Normal } \\
\text { n }(\%)\end{array}$ & $\begin{array}{c}\text { Total } \\
\text { n (\%) }\end{array}$ & \\
\hline \multicolumn{5}{|c|}{ Socio-economic status } \\
\hline Low social class & $69(33.8)$ & $135(66.2)$ & $204(100.0)$ & \multirow{2}{*}{$\begin{array}{l}\chi^{2}=6.14 \\
p=0.013\end{array}$} \\
\hline High social class & $7(15.2)$ & $39(84.8)$ & $46(100.0)$ & \\
\hline \multicolumn{5}{|l|}{ Fever } \\
\hline Yes & $119(65.4)$ & $63(34.6)$ & $182(100.0)$ & \multirow{2}{*}{$\begin{array}{l}\chi^{2}=5.62 \\
\mathrm{p}=\mathbf{0 . 0 1 8}\end{array}$} \\
\hline No & $55(80.9)$ & $13(19.1)$ & $68(100.0)$ & \\
\hline \multicolumn{5}{|l|}{ Vomiting } \\
\hline Yes & $111(73.5)$ & $40(26.5)$ & $151(100.0)$ & \multirow{2}{*}{$\begin{array}{l}\chi^{2}=2.76 \\
\mathrm{p}=0.097\end{array}$} \\
\hline No & $63(63.6)$ & $36(36.4)$ & $99(100.0)$ & \\
\hline \multicolumn{5}{|l|}{ Underweight } \\
\hline Underweight & $15(33.3)$ & $30(66.7)$ & $45(100.0)$ & $\chi^{2}=0.22$ \\
\hline Normal & $61(29.8)$ & $144(70.2)$ & $205(100.0)$ & $\mathrm{p}=0.637$ \\
\hline \multicolumn{5}{|l|}{ Stunting } \\
\hline Yes & $11(30.6)$ & $25(69.4)$ & $36(100.0)$ & $\chi^{2}=0.00$ \\
\hline No & $65(30.4)$ & $149(69.6)$ & $214(100.0)$ & $\mathrm{p}=0.983$ \\
\hline \multicolumn{5}{|l|}{ Wasting } \\
\hline Yes & $15(34.1)$ & $29(65.9)$ & $44(100.0)$ & $\chi^{2}=0.34$ \\
\hline No & $61(29.6)$ & $145(70.4)$ & $206(100.0)$ & $\mathrm{p}=0.558$ \\
\hline \multicolumn{5}{|c|}{ Dehydration status } \\
\hline Dehydrated & $18(26.5)$ & $50(73.5)$ & $68(100.0)$ & $\chi^{2}=0.68$ \\
\hline $\begin{array}{l}\text { No signs of } \\
\text { dehydration }\end{array}$ & $58(31.9)$ & $124(68.1)$ & $182(100.0)$ & $\mathrm{p}=0.409$ \\
\hline \multicolumn{5}{|c|}{ Severity of dehydration } \\
\hline Mild & $10(27.8)$ & $26(72.7)$ & $36(100.0)$ & \\
\hline Moderate & $2(10.0)$ & $18(90.0)$ & $20(100.0)$ & $\chi^{2}=6.23$ \\
\hline Severe & $6(50.0)$ & $6(50.0)$ & $12(100.0)$ & $\mathrm{p}=\mathbf{0 . 0 4 4}$ \\
\hline
\end{tabular}


Among the controls, underweight status $33.3 \%$ underweight versus $10.5 \%$ non-underweight were zinc-deficient, $\left.\chi^{2}=9.25, \mathrm{p}=0.002\right)$ and wasting $(34.8 \%$ versus $\left.10.1 \%, \chi^{2}=11.68, \mathrm{p}=0.001\right)$ were significantly associated with a higher prevalence of zinc deficiency, whereas, stunting $(p=0.189)$ and low social class $(p=0.486)$ were not.

The three patients who died in the course of the study all had a combination of zinc deficiency, severe dehydration and multiple electrolyte derangements.

\section{Discussion}

The mean serum zinc levels of the diarrhoea patients $(78.8 \pm 35.6 \mu \mathrm{g} / \mathrm{dl})$ was significantly lower than that of the controls $(107.3 \pm 46.8 \mu \mathrm{g} / \mathrm{dl})$ in the present study. The prevalence of zinc deficiency was also higher in the patients $(30.4 \%$ versus $12.4 \%$ in the controls). This finding is in keeping with those of the studies by Okolo et $\mathrm{al}^{22}$ and Rani et $\mathrm{al}^{23}$ who also reported lower serum zinc levels in children with diarrhoea. The prevalence of zinc deficiency among the patients in the present study suggests that zinc deficiency is quite common among children with diarrhoea in the study community. In addition, the fact that more than one-tenth of apparently healthy children in the study had zinc deficiency, which could put them at risk of diarrhoea and other problems associated with zinc deficiency, should be of concern. It would therefore be imperative to put in place programmes that will help to make zinc-rich foods more available and affordable to children in the study community so as to reduce the burden of zinc deficiency.

It is not surprising that a significantly higher proportion of the patients belonged to low social class, compared with the controls. This is probably related to the higher prevalence of factors such as poor hygiene, water shortage, poor weaning practices and undernutrition, which predispose to diarrhoea, among people from low social class. ${ }^{12}$ The higher prevalence of zinc deficiency among the 'low social class' group may be related to their restricted access to zinc-rich food items, such as red meat, which are usually expensive..$^{5}$ Such families may be unable to afford these food items, thereby relying more on the cheaper food items such as cereals and legumes, which have low zinc bio-availability as a result of their high phytate content. ${ }^{5}$
The absence of a correlation between serum zinc levels and duration of diarrhoea, as well as frequency of passage of stools, may be due to variations in the premorbid body content of zinc in the patients. Diarrhoeal losses may not be immediately reflected in children who previously had relatively higher levels. On the other hand, haemoconcentration in dehydrated persons can result in apparently higher zinc levels. ${ }^{24}$ This might have contributed to the absence of a significant relationship between dehydration status and zinc deficiency in the present study. However, the higher prevalence of zinc deficiency among the severely dehydrated patients may be a reflection of the propensity of zinc deficiency for causing greater severity of diarrhoea. ${ }^{7}$ Malnutrition was not found to be a significant risk factor for zinc deficiency among children with diarrhoea. A possible reason for this finding is that diarrhoea itself, through zinc losses in the stools, could have been the precipitating factor for low zinc levels in non-malnourished patients. ${ }^{8}$

Although the prevalence of zinc deficiency among the controls is seemingly much lower than that reported from other parts of Nigeria, ${ }^{6,25,26}$ the differences may be more apparent than real because of differences in the definition of zinc deficiency. Using a cut-off value of $80 \mu \mathrm{g} /$ $\mathrm{dl}$, a national prevalence of $20 \%$ was reported from the Nigerian Nutrition survey in $2004,{ }^{6}$ whereas using a cutoff value of $70 \mu \mathrm{g} / \mathrm{dl}$, a prevalence of $21 \%$ was reported among 5-13 year old children in Lagos, Nigeria in $2011 .^{25}$ However, using the same cut-off value of $65 \mu \mathrm{g} / \mathrm{dl}$ as in the present study, a prevalence of $41.5 \%$ (35\% in urban areas and $48 \%$ in rural areas) was reported from under-five children in Imo State, Nigeria in $2011 .^{26}$ The prevalence reported in Imo was even higher than that observed in children with diarrhoea in the present study (30.4\%). The disparity could be related to differences in methods of analysis, as well as the health, socio-economic and nutritional status of the study participants, which were not specified in the Imo study. Differences in the zinc content of soils as well as staple foods across regions may also be contributory. ${ }^{5}$ The disparities in prevalence across these studies underscore the importance of the use of similar definitions or cut-off values in studies of the prevalence of trace element deficiencies. The IZiNCG recommends the adoption of a cut-off value of $65 \mu \mathrm{g} / \mathrm{dl}$ in the definition of zinc deficiency in children. ${ }^{21}$ 


\section{Conclusion}

The study showed that zinc deficiency is significantly associated with diarrhoea in under-five children in the study community. Thus, zinc supplementation should be encouraged in addition to oral rehydration therapy for the routine treatment of childhood diarrhoea, and availability should be ensured. The burden of childhood diarrhoeal diseases will thereby be reduced.

\section{Limitations of the study}

1. Patients and controls were not matched for socio-economic status.

2. Dietary zinc intake was not assessed in this study.

\section{Conflict of interest}

None declared.

\section{References}

1. UNICEF. The state of the World's children 2014 in numbers. online. United Nations Children's Fund; 2014 Accessed 2014 May 12; Available from: URL: http:// www.unicef.org/publications / files/SOWC2014_In_ Numbers_28_Jan.pdfw

2. Charyeva Z, Cannon M, Oguntunde O, Garba AM, Sambisa W, Bassi Ap, et al. Reducing the burden of diarrhoea among children under five years old: lessons learned from oral rehydration therapy corner program implementation in Northern Nigeria. J Health Popul Nutr 2015; $34: 4$.

3. Fraker PJ, King LE, Laakko T, Vollmer TL. The dynamic link between the integrity of the immune system and zinc status. J Nutr 2000; 130: 1399-406.

4. Brown KH, Wuehler SE, Peerson JM. The importance of zinc in human nutrition and estimation of the global prevalence of zinc deficiency. Food Nutr Bull 2001; 22: 113-25.

5. Gibson RS. Zinc nutrition in developing countries. Nutr Res Rev 1994; 7:151-73.

6. Maziya-Dixon B, Akinyele IO, Oguntona EB, Nokoe S, Sanusi RA and Harris E. "Nigeria Food Consumption and Nutrition Survey 2001-2003 Summary". International Institute of Tropical Agriculture, Ibadan. 2004.

7. Bahl R, Bhandari N, Hambidge KM, Bhan MK. Plasma zinc as a predictor of diarrhoeal and respiratory morbidity in children in an urban slum setting. Am J Clin Nutr 1998; 68(Suppl 2): S414-7.
8. Wapnir RA. Zinc deficiency, malnutrition and the gastrointestinal tract. J Nutr 2000; 130:1388-92.

9. WHO/UNICEF. Joint statement: Clinical management of acute diarrhoea. online. World Health Organization, Geneva; 2004 Accessed 30 October, 2012. Available from: URL: http://www.unicef.org/nutrition/files/ ENAcute_Diarrhoea_reprint.pdf

10. Fischer-Walker CL, Fontaine O, Young MW, Black RE. Zinc and low osmolarity oral rehydration salts for diarrhoea: a renewed call to action. Bulletin of the World Health Organization 2009; 87:780-6.

11. Omuemu V, Ofuani I, Kubeyinje I. Knowledge and use of zinc supplementation in the management of childhood diarrhoea among healthcare workers in public primary health facilities in Benin-City, Nigeria. Glob J Health Sci 2012; 4: 68-76 PubMed .

12. WHO. The Treatment of Diarrhoea: A manual for physicians and other senior health workers. 4th revision. World Health Organization, Geneva; 2005. WHO/ CDD/SER/80.2

13. WHO. Planning a health survey; Teaching health statistics. SK Lwanga and Cho-yook (eds). World Health Organization, Geneva. 1986.

14. Atinmo T, Johnson A, Mbofung C, Tindimebwa G. Plasma zinc status of protein energy malnourished children. Acta Trop 1982; 39: 265-74.

15. Mertens K, Lowes DA, Webster NR, Talib J, Hall L, Davies $\mathrm{M}$, et al. Low zinc and selenium concentrations in sepsis are associated with oxidative damage and inflammation. BrJ Anaesth 2015; 114: 990-9.

16. Temiye EO, Duke ES, Owolabi MA, Renner JK. Relationship between painful crisis and serum zinc level in children with sickle cell anaemia. Anaemia 2011; 1: 7-14.

17. Yarhere IE, Ugwu RO, Eneh AU. Serum zinc levels in HIV infected children attending the University of Port Harcourt Teaching Hospital, Port Harcourt, Nigeria. Nig J Paediatr 2014; 41: 110-5.

18. Oyedeji GA. Socioeconomic and cultural background of hospitalized children in Ilesa. Niger J Paediatr 1985; 13: 111-8 PubMed .

19. WHO. WHO child growth standards: methods and development. Geneva: World Health Organization doc; 2006.

20. Greenbaum L. Deficit therapy. In: Kliegman RM, Behrman RE, Jenson HB, Stanton BF, editors. Nelson Textbook of Pediatrics, $18^{\text {th }}$ ed. Philadelphia: Saunders, Elsevier, 2007. p 313. 
21. International Zinc Nutrition Consultative Group (IZiNCG). Assessing population zinc status with serum zinc concentration. IZiNCG Technical Brief 2007; 2:1-4.

22. Okolo SN, Okonji MC, Osuji F, Okoli CA, Okolo NY, Okolo CA. Serum and stool levels of zinc, copper and vitamin A in children aged 6-24 months with diarrhoea. Nig J Paediatr 2009; 36:29-32.

23. Rani K, Sodhi KS, Singh J, Pandey R. Serum zinc levels in children (from six months up to five years of age) suffering from diarrhoea. Curr Trends Biotechnol Chem Res 2014; 4:1-5 PubMed .
24. Strand TA, Adhikari RK, Chandyo RK, Sharma PR, Sommerfelt H. Predictors of plasma zinc concentrations in children with acute diarrhoea. Am J Clin Nutr 2004; 79: 451-6.

25. Akeredolu IA, Oguntona EB. Iron, Zinc and Copper Malnutrition among Primary School Children in Lagos, Nigeria. Food Nutr Sci 2011; 2:1063-70.

26. Onyemaobi GA, Onimawo IA. Zinc Status of Under-Five Children in Rural and Urban Imo State, Nigeria. J Basic Appl Sci Res 2011; 1:451-5. 